\title{
Food and trust in Australia: building a picture
}

\author{
John Coveney* \\ Department of Public Health, Flinders University, Box 2100, Adelaide 5001, South Australia
}

Submitted 8 December 2006: Accepted 29 March 2007: First published online 3 August 2007

\begin{abstract}
Objective: To explore consumer trust in food, especially people's experiences that support or diminish trust in the food supply; consumer practices to strengthen trust in food; and views on how trust in the food supply could be increased. Setting: Adelaide, South Australia.

Design: In-depth qualitative research interviews and focus groups.

Subjects: Women and men who are primary food providers in families $(n=24)$.

Results: Media coverage of food scares and scandals and personal experience of food-borne illness challenged respondents' trust in the food system. Poor retail food handling practices and questionable marketing ploys by food manufacturers also decreased trust. Buying 'Made-in-Australia' produce and following food safety procedures at home were important practices to strengthen food trust. Knowledge of procedures for local food inspection and for national food regulation to keep food safe was scanty. Having a strong regulatory environment governing food safety and quality was considered by respondents to be of prime importance for trust building.

Discussion: The dimensions of trust found in this study are consistent with key theoretical aspects of trust. The need for trust in highly complex environments, in this case the food supply, was evident. Trust was found to be integral to food choice, and negative media reports, the sources of which themselves enjoy various levels of dependability, were found to easily damage trust relationships. The lack of visibility of authoritative monitoring and surveillance, misleading food advertising, and poor retail food handling practices were identified as areas that decreased consumer trust. Respondents also questioned the probity of food labelling, especially health claims and other mechanisms designed to guide food choice. The research highlights the role trust plays in food choice. It also emphasises the importance of a visible authoritative presence in the food system to strengthen trust and provide reassurance to consumers.
\end{abstract}

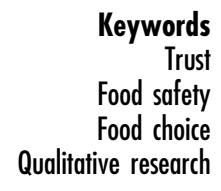

The importance of understanding influences on food choice is fundamental to public health since diet is a major risk factor for many common population health problems, including heart disease, diabetes, cancer and obesity $^{1}$. It is well accepted that food choice is influenced by a range of biological, cultural, economic and psychosocial factors ${ }^{2}$. The role of trust in influencing consumer food choice is taking on increasing importance. Trust is now regarded as a vital component of health and wellbeing $^{3}$. In relation to food and public health, trust is crucial if consumers are to recognise and accept the benefits of new food technologies and feel assured that food regulation is protecting their best interests. In some countries, a lack of trust has had a detrimental effect on public confidence in the integrity of the food supply, leaving consumers vulnerable to misinformation and poor dietary choices ${ }^{4}$.

In Australia, there has been growing concern about the level of consumer trust in food ${ }^{5,6}$. Consumer trust in mechanisms to keep food safe has been challenged by a number of food safety events. In South Australia, for example, over the past 10 years there have been cases of food poisoning involving processed meats ${ }^{7,8}$, some of which have resulted in fatalities. New technological developments in the food supply may also damage trust, especially when the safety of new products is questioned, as in the case where trials of genetically modified peas were halted after an adverse immune response was detected in test animals?.

There is often a lack of congruence between consumer perceptions and the available evidence on which foods can be trusted ${ }^{10}$. For example, a recent survey of 1200 Australian adults found that pesticides, food additives and preservatives gave rise to the greatest uncertainties about food $^{11}$. This is despite the fact that food additives are thoroughly tested and strictly regulated in Australia, and that government market basket surveys show pesticide residues to be nowhere near the levels that public concern 
would suggest. Nevertheless, public concerns should not be dismissed as 'irrational' or 'unfounded'. Public health groups, food regulators and food industry groups in Europe have all learned to their cost that public food trust has a marked effect on confidence in food purchases, the credibility of expert recommendations, food regulation and trust in food industry practices ${ }^{12}$.

In public health nutrition, trust impacts on important areas, namely: (1) food choice, (2) confidence in expertendorsed population dietary guidelines and recommendations and (3) trust in food regulation designed to improve public health nutrition. Damage to trust in these areas can have dramatic public health consequences, as discussed below.

\section{Food choice}

Trust directly affects dietary patterns and food intake, and thus nutritional status. Although the precise nutritional outcomes of altered food choice as a consequence of trust are unknown, dietary modelling shows that essential nutrients can be marginalised by the elimination from the diet of food considered unsafe $^{13}$. Also unorthodox and possibly dangerous eating habits - for example, avoidance of core food groups - can arise when consumers distrust standard regulatory controls ${ }^{14}$.

2. Expert advice

Trust plays an important role in consumer recognition of expert-endorsed dietary recommendations. Efforts to improve public understanding about diet, ranging from Australian government programmes encouraging fruit and vegetables to the National Heart Foundation's 'Pick the Tick' campaign, rely on consumer trust in both the credibility of the message and the probity of the organisation. In the UK, public trust, and thus credibility of dietary messages, has been jeopardised when the 'messenger' is regarded as fallible ${ }^{15,16}$, or when commercial concerns in private-public food campaigns are believed to have overtaken public interests ${ }^{17}$. Concerns have been expressed over the efficacy of health campaigns because the UK public no longer trusts government or expert messages ${ }^{18}$. The extent of this distrust, and its effects on food choice, is unknown but clearly needs to be understood to better plan public campaigns addressing public health nutrition.

3. Food regulation

Trust is integral to public attitudes to food regulatory measures. In Australia, there has been concern that public mistrust of government regulation of some issues (e.g. genetically modified food legislation) may overflow and negate efforts to influence and improve dietary habits through mechanisms like food label$\operatorname{ling}^{19}$. Moreover, the success of the planned introduction of pre-approved health claims on food in Australia is predicated on consumer trust in both the efficacy of the claim and the regulatory mechanism overseeing claim substantiation.

Despite its potential role in influencing public health outcomes, consumer food trust is poorly understood. Indeed, public health interventions are often based on simplistic assumptions of trust that are undertheorised. Inherent in many interventions is an assumption of a linear relationship between scientific evidence, public trust and consumer behaviour. A critique of recent research on lay attitudes to food ${ }^{20}$ demonstrates that a 'knowledge-deficit' model underpins much public health communication. The model assumes that experts' and consumers' knowledge exists within the same technical-rational paradigm, but at different points along a continuum. However, like many human-health interactions, the role played by trust is likely to be multidimensional and complex, and consumers' trust in expert recommendations and regulatory processes is more likely to be the product of a much more complex evaluation of trust and credibility.

Most of the health literature addressing trust arises from risk communication and risk assessment. This literature is limited because trust and risk are, in fact, different phenomena: risk refers to the likelihood of potential harm, whereas trust concerns the judgement or willingness to accept another's power or authority in the midst of uncertainty.

Although some initial research has been undertaken in Scandinavia ${ }^{20}$ and the $\mathrm{UK}^{21}$, Australian research addressing food trust is limited to a survey examining consumer perceptions about environmental health risks ${ }^{22}$ and a qualitative study on consumer food risk $^{23}$. Given the importance of evidence-based research in identifying ways in which consumer trust can influence food choice, acceptance of expert advice and confidence in food regulatory practices, there is a pressing need for research to examine trust in food.

\section{The study}

This paper reports on an exploratory study of food and trust undertaken in Adelaide, South Australia. The aim of the study was to examine the dimensions of consumer trust in food, and was guided by the following broad questions:

1. What are people's experiences that support or diminish trust in the food supply?

2. What are people's practices to strengthen trust in the food they eat?

3. How could trust in the food supply be increased?

Because little is known of food trust in Australia - its determinants and its consequences - a qualitative approach was employed. Qualitative research is useful in examining hitherto unexplored issues; it attempts to 
understand and generate theories or explanations rather than test hypotheses ${ }^{24}$. The flexible nature of qualitative research provides the opportunity to capture rather than prove emerging ideas and themes. Results from qualitative research are not usually generalisable to whole populations, but instead are often used to develop hypotheses for further testing and confirmation.

\section{The sample}

Qualitative research often recruits participants through systematic, non-probabilistic sampling which aims to enlist respondents on the basis of their particular experiences of phenomena, rather than their representation of a population group ${ }^{25}$. In this study, primary food providers in families were recruited. Primary providers are those family members who have the main responsibility for food purchasing and preparation. Based on earlier research ${ }^{26}$, primary food providers are more likely to consider the safety and quality of food purchases. It made sense to target this group to seek their concerns about, and trust in, the food supply.

Participants were recruited via Tan McGregor, a market research company, using an extensive database compiled by the company through active and voluntary recruitment of respondents. Potential participants with the following characteristics were sought:

- have main responsibility for family food shopping;

- be between ages 18 and 65 years;

- be from a range of socio-economic groups.

By these means, primary food providers were recruited from a range of socio-economic position and from different locations in Adelaide, South Australia.

\section{The methods}

Data were collected by in-depth interviews and focus groups. The rationale was to use interviews to build a picture of individual concerns, beliefs and practices, which could be put to focus groups for collective viewpoints - even consensus.

Three researchers (including the author) conducted the first six interviews and met frequently to discuss the issues raised and to further refine the scope of the research in light of emerging data. The author conducted all but two of the remaining interviews, and facilitated the focus groups. An interview schedule served as a prompt and a guide to the interview discussions. As the research progressed, the schedule was modified as new, unanticipated issues arose. By the time the issues were taken up by the focus groups, the schedule had 'stabilised', meaning that it had had no new issues added. The interviews were conducted in the respondents' homes and the focus groups were undertaken in the offices of the recruiting agency. Interviews and focus groups were audiotaped (with permission) and transcribed. All respondents' names were changed. The study was approved by the University Social and Behavioural Ethics Committee.

\section{Data analysis}

The data, which were indexed, coded and managed using NUD-IST version 4, were analysed in three steps. Firstorder analysis began with the collection of the first interviews and comprised a description of the respondents' opinions and views in relation to the issues raised in the interviews. First-order analysis built from the 'ground up' as the researchers reached consensus about themes arising from the data. At the end of the research, these themes were used as overarching issues from which the data could be examined.

Second-order analysis examined the data from theoretically informed perspectives. The issues discussed during the interviews and the focus groups were framed within current commentaries and research on trust. The purpose of this level of analysis is to go beyond description and to generate explanations (or theory) to comment on the ways in which respondents understood and articulated issues of food and trust. A third level of analysis was undertaken to examine the extent to which the research questions were addressed, including new light now shed on the area as a result of this research. These three levels of analysis allow a full explication of the data and provide transparency of the data analysis processes.

\section{Results and discussion}

Twelve participants (four men) were recruited for indepth interviews and two groups of six participants (two men in each group) took part in the focus group discussions. The respondents were from a wide variety of socio-economic positions and age groups (Table 1).

\section{First-order analysis}

Four overarching themes were identified from the interview and focus group data for first-order analysis. These were: (1) knowledge of events that raised issues of food trust; (2) direct experience of food and trust; (3) knowledge of trust mechanism that governed the food system; and (4) views on ways of building trust in the food system.

\section{Knowledge of events that raised issues of food trust}

Respondents were well aware of a number of food scares, including cases of food poisoning, that gained prominence in Australia. Examples of food scares with foods such as processed meats, orange juice and biscuits were 
Table 1 Names (given for research) age, and occupation of participants in interviews and focus groups

\begin{tabular}{lll}
\hline Name & Age & \multicolumn{1}{c}{ Occupation } \\
\hline Interviews & & \\
Arthur & 42 & Security guard \\
Annie & 39 & Pharmacy assistant \\
Clive & 58 & Retired \\
Don & 24 & Engineer \\
Kitty & 43 & Home duties \\
Jody & 36 & Factory worker \\
Kass & 38 & Teacher \\
Kirsty & 26 & Bank assistant \\
Meg & 54 & Nurse \\
Mary & 57 & Retail assistant \\
Nick & 51 & Public servant \\
Robyne & 29 & Horse trainer \\
& & \\
Focus group 1 & & Police assistant \\
Bart & 57 & Photographic assistant \\
Jane & 45 & Retired \\
Sandy & 60 & Pensioner \\
'Spiderman' & 37 & Home duties \\
Bangles & 23 & Personal assistant \\
Lucy & 27 & \\
Focus group 2 & & Retired \\
Paul & & Home duties \\
Kate & 64 & Retired \\
Ellie & 41 & Pensioner \\
David & 60 & Checkout operator \\
Helen & 54 & Secretary \\
Ally & 25 & \\
\hline
\end{tabular}

readily provided. In the last 10 years in Australia generally, and South Australia in particular, there have been some famous cases of food poisoning involving these foods.

Annie: Well the Garibaldi and the Nippy fruit juice episodes.

(interview \#2)

Paul: The only ones that I would remember would be the Nippy's Orange Juice and the Metwurst ones, which got a lot of publicity in the newspaper.

(focus group \#1)

Some respondents remembered cases of food poisoning or a food reaction that had affected them personally or had been experienced by friends or relatives.

Sandy: I had a incident where I came out in a rash after going to a Chinese restaurant one night.

(focus group \#1)

Mary: After eating a pasta dish with a cream sauce [my friend] was the only one of a group that ate that particular pasta and she was violently ill and we could only assume that was what it was.

(interview \#10)

Participants were asked how they were made aware of matters that challenged their trust in food. Both direct experience of food risk (exposure to poor food handling) and indirect experience (reported food scares) were mentioned. In relation to the latter, the media was the most often cited source of information, with word of mouth being another way in which awareness was raised. There was, however, a considerable difference in the trustworthiness of different media sources. Television programmes of an investigative nature, especially when experts gave testimonies or statements, were more trusted than newspapers.

Robyne: More inclined [to trust] TV if they actually speak to the scientists or whoever makes it or whatever, not so much just a reporter going blah, blah, blah, reading off paper.

(interview \# 12)

Similar to an earlier study on food and risk by Lupton ${ }^{23}$, periodicals and magazines like Newsweek were rated as sources of trusted information on food. Some people resorted to the Internet or libraries to follow up stories in order to strengthen trust.

Clive: If it was something that I had an interest in then I'd be inclined to do a bit more searching around perhaps. Sort of go to the library pick up publications ... The Internet's a great place for finding out things, but it's also, anybody can publish anything about all kinds of things. And so obviously you really need to check your sources.

(interview \#3)

\section{Direct experience of food and trust}

The discussions in this area could be separated into three areas: shops and stores selling food; other shoppers; and food manufacturers. Each one is discussed in turn.

Shops and stores. Respondents spoke about the trustworthiness of shops and stores selling food, making the point that sometimes trust was breached by the ways in which food is handled. While the use of safe foodhandling techniques - gloves and hairnets - was seen to boost trust in food safety, it also raised awareness of trust when these practices were not followed or were absent.

Meg: It's amazing how often you go to places, like the pizza place we go to where they touch the food with their hands and scratch their bum and touch it [food]. (interview \#9)

Don: It probably makes you more aware that there's a [food safety issue] because they're obviously wearing it for a reason but it's also how they wear it. Like I said before, with the money in one hand and the glove on the other it's redundant.

(interview \#4)

Concern was especially expressed about foods like cooked and raw meat and fish. These foods were thought to require special handling and were in many ways 
dangerous if handled poorly. Indeed, respondents spoke about their own trusted practices to make food safe keeping food cool, using different chopping boards, following use-by dates.

Other shoppers. The practices of other shoppers, especially in supermarkets where food can be freely handled, also came under scrutiny. Indiscriminate handling of food and the possibility of passing on contamination was a source of comment. Having to place trust in others to keep food from posing a health risk was regarded as inevitable and also problematic.

Kitty: Yeah, I mean you don't usually sort of think about it when you are going to the fruit and veg, but people that have been in there and handled all the things. Yeah and make me wash my fruit and veg before I eat it.

\section{(interview \#7)}

Food manufacturers. Food manufacturers were often found to be in breach of food trust, especially in the area of food labelling. Health endorsements in particular, even by not-for-profit organisations like the Australian National Heart Foundation, were regarded to be open to deceit, as expressed by Ellie in this focus group discussion:

Ellie: It's a matter of question, because I was told that if you pay enough, you can get the tick from the Heart Foundation.

(Other member): I heard that.

Ellie: But you have to pay a lot of money to get a tick on your produce, whether or not its been [tested]. It gets back to the almighty dollar.

(focus group $\# 1$ )

The marketing imperative, whereby food manufacturers are constantly seeking to promote their products over others, was believed to undermine probity in food labelling. The failure of any recognisable government endorsement of labelling, which could be trusted, compounded the problem.

Don: From what you're saying I'd be thinking things like Anti-Cancer Foundation, The Heart [Foundation], the ticks, that sort of stuff. I see all that's there but a lot of it's voluntary, not mandatory which probably isn't the best way of doing it. You do see the nutrition labels, that sort of stuff, and I think they've just changed the ingredient conditions again so, yes, the government is there but I see it more as a choice of an information control rather than an active control.

(interview \#4)

However, labelling of a food as 'Made in Australia' generated considerable trust. In general, respondents were satisfied with the standards of food manufacturing in Australia compared to other countries. Asia in particular was regarded to be a source of foods that might not come up to safety standards and therefore did not warrant trust.

\section{Knowledge of trust mechanisms}

Respondents were asked to discuss any mechanisms or processes that gave them trust in the food supply and to identify who might be responsible for ensuring that trust mechanisms were adequately carried out. The importance of inspection of food and practices, whether this was at the level of the shop, the manufacturer or even borders (for example, quarantine), was strongly emphasised as a trust-building mechanism. Border protection was considered to have effectively protected Australia from problems such as bovine-spongioform encephalopathy and foot-and-mouth disease that had wreaked havoc on the food environment in other countries.

Mary: I do think its important that our borders are kept secure, and that we don't have people wandering in with all sorts of bits and pieces or sending things in or bringing them in with them.

(interview \#9)

There was also awareness of checking and monitoring at the local level; however, there was considerably less certainty about how this actually happened. Respondents held somewhat vague notions about routine checking of food, but were unsure about the ways in which this is carried out; there was an expectation that someone, somewhere was monitoring the food supply. While some respondents were aware of local food inspection systems (e.g. food inspectors), there was almost no awareness of the national food regulator (Food Standards Australia and New Zealand) that sets food standards for the Australian states and territories. However, there was more awareness of quarantine mechanisms to keep food safe, often as a result of experience of airport checks and X-ray screening of baggage that are now part of international flight arrivals. And while there was an understanding that bovinespongioform encephalopathy ('mad cow disease') was not yet in Australia, there was little understanding of the mechanisms that made this the case.

\section{Belief in ways of building trust in food}

Overall the importance of trust in the food system was regarded as axiomatic for the respondents in interviews and focus groups. Being able to have confidence in a system that ensured food was safe and of high quality was paramount. Respondents talked about the pressures of a busy lifestyle and the need to feel confident that the food supply was adequately monitored for safety and quality. It was also regarded as something to expect from a wealthy country, as one respondent put it.

Kass: Umm, we like to think we live in a pretty safe, wealthy country and economy... It would be nice 
to know that they are looking after us by making sure that the food we get is top quality or at least monitored or regulated.

$$
\text { (interview \#7) }
$$

Another went further by saying that for them it was 'a matter of life or death' (Paul, focus group \#2). Others talked about the economic costs of a lack of trust, citing the bankruptcy of companies whose products had been the cause of food poisoning, but extending this to a national level. Respondents were well aware of the problems with food scares and scandals that had happened in other countries, especially in Europe, and were grateful that these did not exist to the same extent in Australia. Having to be suspicious of food was a prospect that respondents did not relish and they were grateful that there were systems that could be counted on to keep things safe. There was a belief that systems of monitoring were in place and that people were doing their job.

Bangles: I think its just like the ACCC.* You know its there but you just have to assume they are doing their job.

$$
\text { (focus group \#1) }
$$

Some respondents took steps to build trust into their own food practices by, for example, not eating meat or avoiding additives and chemicals wherever possible. In terms of the wider system, some respondents believed that there was room for improvement. For example, respondents who had worked in different parts of the food industry were cynical of the checks that occurred, like the pre-warning of inspection of food premises.

Annie: Well I think often they pussyfoot around. I worked in a bakery where we used to know when someone would come in to do an inspection, so how ridiculous is that.

(interview \#2)

Others were apprehensive about the outsourcing of inspection to the private sector citing the failure of government to do the job properly. However, one respondent who had been an elected member of a local council had first-hand knowledge of this and was comfortable with outsourcing to a profit-making concern.

Clive: I have spoken to the people there in my role at work [as local government councillor] so I know the people, I know the process and I know that there are very responsible group. So that's why I don't have problems.

(interview \#3)

The lack of a presence of food governance was believed to be something that had to be improved. The visibility of

*ACCC - Australian Competition and Consumer Commission is an independent federal level 'watchdog' that administers the Trade Practices Act, 1974. trust mechanism - where people could see evidence of government involved in monitoring and auditing the food supply - was believed by many to be a trust-building activity.

Don: We've got a register of national estate, we know what's been heritage listed and that sort of stuff, a register of trustworthy manufacturers, suppliers or just a label - like you get the plaques for a heritage listed building.

Interviewer: So some kind of endorsement?

Don: Yes, an endorsement, that sort of thing.

(interview \#4)

Strengthening food labelling was also seen as a way of building trust. A number of respondents, in interviews and focus groups, talked about their lack of trust in how food was labelled and how this was sometimes misleading.

Sandy: I think sometimes its very misleading. Like, you pick up something, like a juice for example, like orange juice, and you start to really look at, and what legally they are allowed to call orange juice, I mean, you know, sometimes it has only got a 35\% component of actual fruit juice and the rest of its water or something else. It is a little bit misleading.

(focus group \#1)

In summary, the interviews and the focus groups raised a number of concerns reflecting the levels of trust people had in food and the systems that govern its quality and safety. There was a degree of faith that abstract systems kept food safe; however, personal experiences made some respondents distrustful of the local mechanisms e.g. retail shops - that brought food to them. To frame these views and opinions more analytically, second-level analysis is used.

\section{Second-level analysis}

Trust is a complex and diffuse phenomenon. It is not easy to measure or define with accuracy. However, a number of commentators have written about trust in detail drawing out some important analytical considerations. Here, key theoretical perspectives are used to provide a more in-depth understanding of respondents' views on food and trust.

\section{The need for trust}

In complex societies where labour divisions lead to specialisation and differentiation of tasks, trust is imperative. Because of the sheer impossibility of undertaking all the necessary tasks for everyday living, the efforts of others must be relied upon to provide the essentials for living, such as food. Indeed, the division of labour between those who produce and manufacture food and those who consume it has arguably never been greater ${ }^{27}$. Thus, the need for consumers to have trust in the system which 
brings food to them is fundamental. Evident in the discussions with individuals and focus groups in this research was a resignation that responsibility for food production and manufacture had to be delegated. The idea of trusting delegated responsibility is not new, and

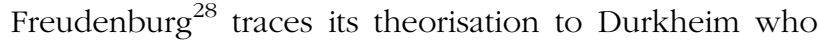
wrote more than 100 years ago on the division of labour and complexity of task.

Even though respondents were resigned to invest trust in others in the food supply, this was not done lightly or without consideration. Respondents were mindful of the fragility of the trust they had in the food supply, and talked about times when they were less trusting of a system which was often difficult to understand and follow. So on the one hand while respondents knew they had to rely on trust, they were also mindful of reported cases of food risk which challenged trust.

\section{The asymmetry of trust}

Trust asymmetry was discussed by Slovic ${ }^{29}$ to refer to the observation that negative reports of safety and quality are usually given higher priority than positive reports. That is to say, consumers are more likely to hear about, notice and remember the number of times things go wrong with the food system than the number of times things go right. Trust asymmetry was a feature of the interviews and focus groups in this research, and respondents talked about the their distrust of food producers, manufacturers, retailers and even other shoppers, all of whom it was believed had the potential to introduce risks to health and safety into the food supply. In comparison, there were fewer comments on the ways producers, manufacturers, etc. kept the food supply safe. In other words, there was a negative bias when considering the contributions of food supply stakeholders.

Respondents spoke of developments that challenged their trust in the food supply. Sometimes these were rather abstract, like genetically modified foods, which were believed to reside hidden in the food supply. Other developments that were more visible and tangible, however, raised concerns about food trust. For example, the recent introduction of safe food handling methods in supermarkets and shops was often commented on. The use of hairnets, gloves and tongs especially in the sale of cooked or raw meat was often regarded as a source of distrust than trust. Having been exposed to hygienic foodhandling practices, respondents' awareness was heightened so that they took special note of poor practices. In other words, they were more likely to engage in trust asymmetry by focusing on risks rather than on benefits.

\section{Social trust}

Frewer et $a l^{30}$ define social trust as people's willingness to be confident in experts and institutions who manage risks for them. Poppe and Kjaernes ${ }^{31}$, in a six-country study on food trust, showed that in those countries where social trust is high - for example, when there is optimism about 'truth telling' by institutions vested with the responsibly for managing food risk - there is a greater belief that food items are safe to eat. For the respondents in research, reported here, however, social trust was generally low. There was a high degree of suspicion and doubt about the management of the quality and safety of the food supply by various government bodies. And while there was a belief that mechanisms were in place to monitor and survey the food supply for safety and quality, a lack of visibility of these mechanisms raised doubts about their effectiveness. There was an expressed need by respondents to be eyewitness to safety- and qualitymonitoring processes. The reassurance through, for example, government-endorsed labels to guide consumers' food purchases was also believed to be lacking. Respondents believed that food labelling was mostly about marketing and promotion of food, rather than about quality, nutrition information or education.

\section{Third-level analysis}

Unlike consumers in some countries where a number of food scares and scandals have damaged trust in food and the governance of the food system ${ }^{32}$, Australians have not experienced national food trust problems ${ }^{23}$. Even so, respondents in this research spoke at length about food safety issues that had an impact on consumer confidence in the food supply. In terms of the research questions that framed this study, the following comments can be made.

In relation to the first question that addressed respondents' experiences that supported or diminished trust, respondents were more likely to experience distrust of, rather than trust in, the safety and quality of food. That is to say, there was little mention of experiences that supported food trust. There are two possible reasons for this. It may have been that the kinds of issues put to respondents for them to consider in interviews and focus groups guided them towards more negative rather than positive issues. The tone and nature of questions, prompts and probes guided by the interview schedule can drive the responses of qualitative discussions ${ }^{33}$. However, the schedules for interviews and focus groups were carefully worded to be as neutral as possible and not steer respondents to any particular direction so it is unlikely that the questions were biased. A much more likely cause of a focus on distrust is the asymmetric nature of trust, discussed earlier, which tends to emphasise a negative rather than positive experiences of trust. There was a view that trust has to be earned and could easily be lost.

Secondly, in terms of ways of strengthening food trust, respondents discussed a range of practices that helped them gain trust in food. These included avoidance of foods or shops which were considered suspicious or even harmful; checking and monitoring at point of purchase; and home-based handling techniques that kept food safe, washing fruits and vegetables, etc. Sometimes this included making meals from basic ingredients and avoiding 
so-called 'processed' foods. In some countries, consumers have increased use of organic food as a way of gaining confidence in their food supply ${ }^{34}$. In this research, organics were not used to any great extent by respondents. This may be because the organic industry in Australia is less well developed than some other countries. Also respondents talked about the problems in identifying organic food for purchase and this made trust a difficult proposition.

Lastly, in terms of increasing trust in food there are some general points worth noting. There was a voiced need for greater authoritative presence to either endorse good practice or counter market-oriented promotions. The lack of visibility of authoritative endorsement in the food marketplace made respondents in this research suspicious of adequate monitoring and surveillance of the food supply. There was also cynicism in both the interviews and focus groups about the honesty of food labelling, especially in terms of health endorsements. Rather than see some food labelling as genuine efforts to inform the public and guide food choice, food labels were overall considered as ploys to provide manufacturers with a marketing edge.

\section{Implications of this study}

As an exploratory study, this research attempted to build a picture of key issues of food trust for Australian consumers. Other research has demonstrated that consumers' trust in food eaten is very dependent on specific contexts and local experiences ${ }^{31}$. Thus, the extent to which consumers in other countries may experience the degrees of (mis)trust presented here might be argued. Even within Australia, different experiences of consumers may well temper views on food trust. South Australians in particular have been exposed to a number of highly publicised cases of food poisoning and poor food practice in recent years, which were reflected in this research.

While the small number of respondents recruited is appropriate for an exploratory qualitative study, it does place limitations on examining any differences in response across gender and socio-economic groups. What the research provides is a broad view of participants' views on trust in the food supply, substantiated by in-depth interviews and focus groups. The implications may be summarised as follows. Firstly, trust is integral to food choice and negative media reports, the sources of which themselves enjoy various levels of dependability, can easily damage trust relationships. Moreover, the perceived lack of visibility of trust-building mechanisms makes it difficult for consumers to develop trust and counter negative reports. Secondly, the market-competitive nature of the food supply led to a general belief expressed in this research that stakeholders in the food supply are purely vested in profit-making. This was true even for organisations like the National Heart Foundation that aim to reform the food supply by encouraging the manufacture of healthier foods. There are implications here for health claims labelling, which is being introduced in Australia soon. While reassurances on the rigorous control of health claims have been pledged ${ }^{35}$, this research suggests that health claims are likely to meet with consumer cynicism unless government endorsement is clear and visible. There are also implications for frontof-packet food labelling using a traffic-light guide system, which have been discussed in Australia as a mechanism to make the selection of healthier foods easier ${ }^{36,37}$. In the UK, food supply reforms that have attempted to 'put the consumer first' have not always served to further consumers interests ${ }^{38}$. It would appear from this research that South Australian consumers tend to be suspicious of any reforms or developments that purport to protect them but, in the process, diminish the presence of a dependable and trustworthy authority in the food system. Of paramount importance is a visible government presence that strengthens trust in the system and provides reassurance to consumers.

\section{Acknowledgements}

Sources of funding: This research was funded by The Flinders University Institute of Health Research (project no. 2538).

Conflict of interest declaration: None declared.

Authorship responsibilities: The author was chief investigator and project manager and was involved in all stages of the study, including securing project funding, study conceptualisation and design, data collection and analysis, and manuscript preparation.

Acknowledgements: The author would like to thank Ellie Rosenfeld, Stacey Masters and Tuesday Udell for their help with interviewing participants for this study, also Marika Tiggemann for early discussions on food and trust.

\section{References}

1 Australian Institute of Health and Welfare (AIHW). Chronic Diseases and Associated Risk Factors in Australia, 2001. Canberra: AIHW, 2002.

2 Murcott A, ed. The Nation's Diet: The Social Science of Food Choice. London: Longman, 1998.

3 Baum F. The New Public Health: The Australian Experience. Melbourne: Oxford University Press, 1998.

4 Lang T, Heasman M. The Food Wars, Public Health and the Battle for Mouths Minds and Markets. London: Earthscan Publication, 2004.

5 Coveney J. Food security and sustainability: are we selling ourselves short? Asia Pacific Journal of Clinical Nutrition 2000; 9: S97-100.

6 Australian Competition and Consumer Commission. ACCC watches new labelling of GM foods [online], 18 January 2002. 
Available at http://www.accc.gov.au/content/index.phtml/ itemId/87952. Accessed 29 March 2007.

7 Beers M. Haemolytic-uraemic syndrome: of sausages and legislation. Australian New Zealand Journal of Public Health 1996; 20(5): 462-6.

8 Anon. Listeria widow searches for answers. Adelaide Advertiser, 30 December 2005; 2.

9 Prescott V, Campbell P, Moore A, Matles J, Rothenburg ME, Foster PS, et al. Transgenic expression of bean alphaamylase inhibitor in peas results in altered structure and immunogenicity. Journal of Agriculture and Food Chemistry 2005; 53(23): 9023-30.

10 Sjoberg L. Limits of knowledge and the limited importance of trust. Risk Analysis 2001; 21(1): 189-98.

11 Williams P, Stirling E, Keynes N. Food fears: a national survey on the attitudes of Australian adults about the safety and quality of food. Asia Pacific Journal of Clinical Nutrition 2004; 13(1): 32-9.

12 Lang T. The complexities of globalisation: the UK as a case study of tensions within the food system and the challenge to food policy. Agriculture and Human Values 1999; 16(2): 169-85.

13 Cade J, Calvert C, Barrett J. How could the BSE crisis affect nutrient intake? Comparison of beef and non-beef eating meat eaters from the UK Women's Cohort Study. European Journal of Clinical Nutrition 1998; 52(5): 151-2.

14 Lea E, Worsley A. Influences on meat consumption in Australia. Appetite 2001; 36(2): 127-36.

15 Masood E. UK panel formed to rebuild trust in government science advice. Nature 1999; 397(6719): 458.

16 Coulson NS. Source of food safety information: whom do adolescents trust? Appetite 2002; 38(3): 199-200.

17 Food Commission. Cause or Compromise?: A Survey into Marketing Partnerships between Food Companies and Health Charities or Medical Associations. London: The Food Commission, 2002.

18 Coombes R. Public distrusts government health campaigns, experts say. British Medical Journal 2005; 331(7508): 70.

19 Anon. Trust food labels. Adelaide Advertiser, 19 January 2002; 51.

20 Hansen J, Holm L, Frewer L, Robinson P, Sandoe P. Beyond the knowledge deficit: recent research into lay and expert attitudes to food risks. Appetite 2003; 41(2): 111-21.

21 MacIntyre S, Reilly J, Miller D, Eldridge J, eds. Food Choice, Media Scares, and Health: The Role of the Media. Harlow: Longman, 1998.
22 Starr G, Langley A, Taylor A. Environmental Health Risk Perceptions in Australia: A Research Report to the enHealth Council. Adelaide: Centre for Population Studies in Epidemiology, South Australian Department of Human Services, 2000.

23 Lupton DA. Lay discourses and beliefs related to food risks: an Australian perspective. Sociology of Health and Illness 2005; 27(4): 448-67.

24 Liamputtong P, Ezzy D. Qualitative Research Methods, 2nd ed. South Melbourne: Oxford University Press, 2005.

25 Mays N, Pope C. Rigour and qualitative research. British Medical Journal 1995; 311(6997): 109-12.

26 Coveney J. Food, Morals and Meaning: The Pleasure and Anxiety of Eating. London: Routledge, 2006.

27 Fischler C. Food, self and identity. Social Science Information 1988; 27(2): 275-92.

28 Freudenburg W. Risk and recreancy: Weber, the division of labor, and the rationality of risk perception. Journal of Social Issues 1993; 71(4): 909-32.

29 Slovic P. Perceived risk, trust and democracy. Risk Analysis 1993; 13(6): 675-82.

30 Frewer L, Lassen J, Kettlitz B, Scholderer J, Beekman V, Berdal KG. Societal aspects of genetically modified foods. Food and Chemical Toxicology 2004; 42(7): 1181-93.

31 Poppes C, Kjaernes U. Trust in Food in Europe. Oslo: National Institute for Consumer Research, 2003.

32 Lang T. Food industrialisation and food power: implications for food governance. Development Policy Review 2003; 21(5-6): 555-68.

33 Oakley A. Interviewing women - a contradiction in terms. In: Roberts H, ed. Doing Feminist Research. London: Routledge \& Kegan Paul, 1981.

34 Sirieix L, Schaer B. Buying Organic Food in France: Shopping Habits and Trust [online], 19 December 2005. Available at http://ideas.repec.org/p/wpa/wuwpot/ 0512010.html. Accessed 30 May 2007.

35 Food Standards Australia New Zealand (FSANZ). Nutrition, Health and Related Claims. Canberra: FSANZ, 2005.

36 Zimmet P, James P. The unstoppable Australian obesity and diabetes juggernaut: What should politicians do? Medical Journal of Australia 2006; 185(4): 187-8.

37 Beard T, Nowson C, Riley M. Traffic-light food labels (letter). Medical Journal of Australia 2007; 1(1): 19.

38 Rothstein $\mathrm{H}$. Escaping the regulatory net: why regulatory reform can fail consumers. Law and Policy 2005; 27(4): $520-48$. 